Mindfulness and Speed Testing for Children with Reading Disabilities: Oil and Water?

Julia Keller, Ph.D.

University of New Mexico

Eric Ruthruff, Ph.D.

University of New Mexico

Patrick Keller, Ph.D.

University of New Mexico

This study was supported by the Mind and Life Institute under Grant \#2011-01-004.

Correspondence concerning the article should be directed to Julia Keller, email:

jkelle01@unm.edu 


\section{Mindfulness and Speed Testing for Children with Learning Disabilities: Oil and Water? ABSTRACT}

Metacognitive approaches are important in teaching reading skills, but little is known about how to develop self-regulation through classroom interventions. This study reports results from a randomized controlled pilot trial in which we investigated whether mindfulness-based training improves literacy scores/attitudes in children with a learning disability (LD). Mindfulness is a well-established metacognitive strategy for developing attention and has been shown to reduce anxiety and cognitive interference and improve positive affect. These benefits might help students with LD come to terms with their disability and improve their reading skills. Twenty elementary students with LD were randomly assigned to active control or experimental group that received a five-week intervention incorporating reading instruction and mindfulness. Quantitative results showed that training significantly increased response times during decoding (indicating possible increases in reflectiveness) and lowered heart rate. Qualitative analysis revealed themes pointing to improvements in literacy and affect. Implications for intervention and assessment are discussed.

Keywords: learning disabilities, mindfulness, metacognition, speed testing, self-efficacy 


\section{Mindfulness and Speed Testing for Children with Reading Disabilities: Oil and Water?}

The cause of learning disabilities (LD) that affect reading skills is widely held to be a deficit in the phonological processing of sounds in language (Aylward et al., 2003; Eden et al., 2004; Vellutino, Fletcher, Snowling, \& Scanlon, 2004). Consistent with this view, children with LD have difficulty deciding which words start with the same sound and cannot segment or blend the sounds in a word (e.g., "chat" is segmented into the sounds "ch," "a," and "t," and blending these separate sounds makes the word "chat"). For older children who have accumulated a limited sight word vocabulary, their phonological impairment is particularly marked when they are asked to read nonsense words (like "twale") that can be deciphered only by using decoding (phonological) strategies.

Many intervention studies of children with LD have reported improvement in children's word attack and decoding skills, but these gains failed to generalize to other types of reading tasks. "In fact, generalization of remedial gains has proved a formidable hurdle for many intervention methods reported in the literature..." (Lovett, Lacerenza, \& Borden, 2000, p. 459). Numerous researchers have documented that children with LDs are passive learners who seldom transfer newly acquired strategies to new learning tasks (Borkowski, Estrada, Milstead, \& Hale, 1989).

The overall ineffectiveness of existing remediations might be because they do not address metacognitive deficits common to children with LD. Borkowski et al. (1989) proposed a model of metacognition for children with general LDs who have I.Q.s between 80-95 (a range that would include 11 of the 18 participants in the present study). These children are slow learners who have repeatedly failed in academic situations, are easily distracted, and have low selfconfidence and self-esteem. They are chaotic and inconsistent in applying learned strategies to solving problems as a result of deficiencies in executive processes and low self-worth that depresses mood and raises anxiety (Steca et al., 2014). Borkowski et al.'s metacognitive model is especially applicable for these types of children, but is also relevant to children with specific learning disabilities, who have more well-defined deficits in areas such as math or decoding and who experience metacognitive failures that inhibit their use of reflective processes during novel tasks.

Even when children with learning disabilities are taught specific learning strategies and how to apply them, they have difficulty monitoring whether or not they are using the strategy 
correctly and efficiently (Lovett et al., 2000). Self-instruction training (or guided self-talk) may help develop self-monitoring skills and self-regulation (Harris, Graham, Brindel, \& Sandmel, 2009). Bornstein and Quevillon (1976) investigated the efficacy of self-instructions on improving on-task behavior in three overactive preschool boys with generalized learning problems. At the beginning of each two-hour session, the child watched the experimenter modeling overt self-verbalizations after which the child completed the task with covert selfinstructions. Mean rates of on-task classroom behavior increased from baseline $(10.4 \%, 14.6 \%$, and $10 \%$ for each child) to post-treatment $(82.3 \%, 70.8 \%$, and $77.8 \%$ for each child), suggesting successful transfer from the experimental tasks to the classroom. Importantly, the benefits were maintained at a follow-up assessment 22.5 weeks after training.

Because of a long record of academic failure, children with learning disabilities do not believe that their efforts will improve their performance or that they can succeed in school tasks (Borkowski et al., 1989; Seyed, Salmani, Nezhad, \& Noruzi, 2017). A child's beliefs about selfefficacy, stemming from prior use of strategies and the consequences of those strategic attempts, determine whether or not a child will continue to use the strategy or give up entirely, believing themselves unable to do the task. Given the importance of self-efficacy, a different approach to intervention might include the remediation of self-efficacy, as well as phonological processing. Important to the development of motivation, persistence, resilience, and skillful performance, self-efficacy can be promoted by a warm and responsive environment, the encouragement of exploration and curiosity, setting goals that are specific, short-term, and challenging but attainable, and performance feedback that focuses on developing self-awareness of strengths and limitations (Schunk \& Pajares, 2001).

In a twenty-year longitudinal study of adults with LDs, Raskind, Goldberg, Higgins, and Herman (1999) collected data using public records, a life stressor checklist, cognitive and academic testing, and in-depth interviews. Qualitative analyses of interviews revealed a set of success attributes: perseverance, proactivity, emotional stability, goal setting, social support systems, and self-awareness. A quantitative analysis was conducted to determine predictors of success in employment, education, independence, family relationships, community relations/interests, and crime/substance abuse. Success attributes explained 49 to $75 \%$ of the variance, with either IQ or achievement making a minor contribution (0-5\%), depending on which outcome variable was used in the regression. Thus, success attributes differentiated 
between successful and unsuccessful individuals, with successful adults demonstrating greater self-awareness and self-acceptance of their learning disability.

Therefore, since Raskind et al.’s (1999) results suggest that developing self-awareness and self-acceptance of strengths and limitations is a predictor of success in adults with LDs, interventions for children with LDs should include training that increases self-awareness and self-acceptance, or attributional beliefs (self-efficacy), as well as training of executive processes needed to implement problem-solving strategies (Borkowski et al., 1989). Executive functions are typically viewed as cognitive processes used to self-regulate thoughts and goal-directed behaviors (Alvarez \& Emory, 2006). Learners who develop self-regulation or metacognitive control - cognitive control informed by self-monitoring (Serra \& Metcalfe, 2009) — are able to monitor their attention, retention, motivation, and self-awareness of thoughts, feelings, and actions in order to attain their learning goals (Zimmerman \& Moylan, 2009). Zimmerman and Moylan's cyclical phase model of self-regulation includes a forethought phase where goal setting and strategic planning occur, along with determining self-motivation beliefs (e.g., task interests and self-efficacy). During the performance phase, self-observation and self-control occurs, using time management, help-seeking, self-instructions, imagery, etc. During the self-reflection stage, self-judgment and self-reaction occur, where the student decides if they are satisfied with their performance and if they will use/modify current strategies or, due to a low self-evaluation, find ways to avoid the task.

A metacognitive approach that includes training in self-awareness, self-acceptance, and self-regulation and that has promise to promote generalizable gains in literacy skills among children with LD is mindfulness. Mindfulness is a well-established technique for developing attentional capacities and emotional stability in adults and can be considered a metacognitive skill. It has been operationally defined by Bishop et al. (2004) as the self-regulation of attention involving sustained attention, attention switching between tasks, and the inhibition of elaborative processing. It is also described as systematic training focused on developing meta-awareness (self-awareness) (Vago and Silbersweig, 2012). Most of the research conducted on mindfulness over the past 20 years has been in the area of health psychology, where studies have consistently demonstrated benefits, including reduced pain and stress and an increase in positive emotion (Davidson et al., 2003; Majumdar, Grossman, Dietz-Waschkowski, Kersig, \& Walach, 2002; Tang \& Posner, 2009). So, many would ask, because mindfulness training is clearly linked to 
health outcomes, why focus on the cognitive benefits of mindfulness? The answer to this question is that changing mental processes has been the focus of mindfulness training for thousands of years (Wenk-Sormaz, 2005).

In a search of 4515 articles in five databases, Chiesa, Calati, and Serretti (2011) found 23 controlled studies that provided objective measures of cognition following mindfulness training in adults. Ten studies assessed sustained attention, eight assessed selective attention, nine assessed executive attention, and four assessed attention switching. Overall, Chiesa et al. found that beginning phases of mindfulness training aimed at developing focused attention were associated with significant improvements in selective and executive attention (working memory). Later stages of mindfulness training, described as an open monitoring of internal and external perceptions, were associated with the improvement of unfocused sustained attention skills.

One of the studies included in Chiesa et al.'s (2011) meta-analysis was Jha, Krompinger, and Baime's (2007) investigation of the effect of mindfulness training on particular aspects of attention, as assessed by the Attention Network Test (ANT; Fan, McCandliss, Sommer, Raz, \& Posner, 2002). They recruited three groups of 17 participants: (a) experienced meditators who practiced concentrative meditation at a one-month intensive retreat (the first experimental group), (b) novice meditators receiving instruction on mindfulness-based stress reduction (MBSR; see Kabat-Zinn, 2003) at the University of Pennsylvania (the second experimental group), and (c) novice meditators from the same population, but who had not yet received MBSR training (the control group). The experienced meditators demonstrated superior conflict monitoring performance compared to the control group and the second experimental group before they received MBSR training. There was a significant difference across groups for response time $(\mathrm{RT})(p<.03)$ and accuracy $(p<.001)$. Furthermore, the second experimental group demonstrated significantly improved spatial orienting following MBSR training compared to before (approximately $30 \mathrm{~ms}$ shorter RT on average at the second time point — after MBSR training - than the first group and the control group combined at the second time point). These results suggest that mindfulness training increases voluntary, top-down attentional skills such as orienting, or the direction and constraint of attention to specific inputs, and conflict-monitoring, or selecting between competing responses.

Another type of attentional skill is control over working memory (WM). Chambers, Lo, and Allen (2008) found evidence that 20 novice meditators, in contrast to 20 controls, 
significantly increased on a measure of WM after a ten-day mindfulness meditation retreat. Jha, Stanley, Kiyonaga, Wong, and Gelfand (2010) examined WM capacity and mood of military personnel as they prepared for active military service in a war zone before and after an MBSR program, dividing participants into those who practiced meditation frequently versus those who practiced rarely. The study used an operation span task (Ospan) as the measure for WM; Ospan involves remembering letters over brief intervals while solving simple math problems. Results showed that frequent meditators maintained both their working memory (WM) capacity and their positive mood over the course of training, despite the stresses of preparing for combat, whereas the infrequent meditators suffered deterioration in both abilities.

Numerous studies on mindfulness in adults have also found that it diminishes anxiety (Davidson, 2010), a notable symptom of LD that particularly needs remediation. Students with LD and ADHD often experience higher levels of trait and state anxiety than their non-impaired peers, especially during testing and problem-solving (Fisher, Allen, \& Kose, 1996; Alesi, Rappo, \& Pepi, 2014). Connolly (1969) observed that dyslexic children react more impulsively than controls during testing and Dean and Rattan (1987) discovered that children with LD responded more negatively to reading failure and had greater difficulty recovering from this stress. Other researchers have also found that children with LDs exhibit higher levels of school anxiety than their non-disabled peers (Alesi et al., 2014) and this leads to the development of poor motivational, coping, and task strategies (e.g., proneness to cheating and making careless errors, negative self-evaluation, trouble concentrating, and daydreaming). These strategies further increase test anxiety and exacerbate the cognitive interference that children with LD experience during learning and testing (Swanson \& Howell, 1996).

Sarason, Sarason, Keefe, Hayes, and Shearin's (1986) cognitive interference model asserts that what people think about during a task affects their behavior. For example, if a person thinks repetitive negative thoughts during a test (e.g., "I don't know any of the answers," and "Everybody else is doing better than me"), they may fail to discriminate subtle differences between answers on a multiple-choice exam. Their attention is divided between self-relevant and task-relevant variables, in comparison to the person with low anxiety who can move her instructional focus away from distracting information, thus increasing WM space (Alesi et al., 2014). Instructions to focus attention (a type of mindfulness) on the current task have been shown to greatly improve the performance of subjects with high anxiety (Sarason et al., 1986). 
Despite the many reasons outlined above that mindfulness would benefit children, controlled studies on mindfulness and cognition in children are very limited and have numerous methodological issues (see Meiklejohn et al., 2012). Studies on the effect of mindfulness on children and/or adolescents with LD are even rarer. Using a pre-post, no-control design, Beauchemin, Hutchins, and Patterson (2008) conducted a pilot study on the use of mindfulness with 32 adolescents attending a private school for students with LD. For 5 to 10 minutes at the beginning of each class period, for a period of 5 weeks, students focused attention on their breath and intentionally observed thoughts and feelings in a nonjudgmental manner. Students and two classroom teachers completed the Social Skills Rating System (SSRS; Gresham \& Eliot, 1990) before and after training, and students also filled out the State-Trait Anxiety Inventory (STAI; Spielberger, Gorsuch, \& Lushene, 1970). Post intervention scores on the STAI indicated that participants demonstrated decreased state and trait anxiety $(p<.05)$. The student SSRS forms showed that the LD students thought their social skills had increased $(p<.05)$. The teacher SSRS forms reflected the teachers' beliefs that their students had significantly improved behaviorally, socially, and academically $(p<.05)$. While the surveys used in this study were subjective measures, and as such were especially prone to demand characteristics, these outcomes are consistent with a cognitive-interference model of LD: Low performance of anxious individuals is caused by problems with attentional focus, self-efficacy, and a tendency to perseverate on selforiented and negative thoughts (Beauchemin et al., 2008). In their conclusion, the authors postulated that methods like mindfulness and relaxation training reduced cognitive interference, allowing students to focus on their work without anxiety.

Although studies of mindfulness in children with LD are rare, a study by Tarrasch, Berman, and Friedmann (2016) on adults suggests it might be effective. In a sample of 19 adults (12 with dyslexia and 13 with ADHD — six had both dyslexia and ADHD), Tarrasch et al. investigated whether or not mindfulness would affect the types of reading errors dyslexics make. The dual-route hypothesis (Pritchard, Coltheart, Palethorpe, \& Castles, 2012) describes two separate mechanisms involved in reading aloud: the lexical route or the immediate visual recognition of a word or the sublexical route, where readers "sound out" a word. After completing a two-month mindfulness workshop, Tarrasch et al. found that (in comparison to a control group of dyslexics [ $n=16]$ whose error rate did not change after 3 months), the average error rate during reading decreased significantly from $12.7 \%(S D=6.4 \%)$ before the workshop 
to $9.7 \%$ after the workshop $(S D=4.5 \%, p=.02, d=.75)$. Looking at errors by type, surface errors - resulting from reading via the sublexical route - was the only type that decreased significantly $(p=.01)$. When comparing dyslexic participants with and without ADHD, only those with ADHD had a significant reduction in reading errors $(p=.04)$. The authors concluded that mindfulness improved reading by keeping participants on the lexical route due to improved sustained attention and reduced impulsivity. There were also significant improvements in all participants in perceived stress, rumination, depression, anxiety, and sleep-disturbances.

Since these two studies indicate that mindfulness ameliorates some of the symptoms of LD in adolescents and adults, we wanted to know the impact of mindfulness in children with LD: Does it improve decoding and writing skills, use of metacognitive strategies during decoding, and increase self-awareness, self-efficacy, and positive affect during instruction?

\section{Methods}

\section{Participants}

After approval by the University of New Mexico's IRB, twenty students from grades 2 through 5 were recruited from a school district in the Southwest who had been determined to have a Specific Learning Disability (SLD) by the school's Eligibility Determination Team (EDT). According to the New Mexico Public Education Department (2011), after implementing the three-tiered Response to Intervention model, a child is identified as SLD if the following three conditions are met:

1. The child demonstrates significant academic underachievement that is documented and supported by a pattern of strengths and weaknesses in performance and/or achievement. This underachievement persists despite sustained, high-quality, scientific, research-based instruction and intervention.

2. There is evidence of basic neurological processing deficit(s).

3. The child's challenges are not caused by the following exclusionary factors: Lack of appropriate instruction in reading or math; limited English proficiency; visual, hearing, or motor disability; intellectual disability; emotional disturbance; cultural factors or environmental or economic factors (pp. 185-186).

The participants were first matched in pairs (as well as possible) on age, sex, English Language Learner (ELL) status, and level of service (see Table 1) and then the pairs were randomly assigned to either the experimental group $(n=10)$ or the active control $(n=10)$. Two 
of the students in the control group whose parents gave consent did not show up for the intervention and so were dropped from the study. Overall, seven girls and eleven boys participated in this study. Seventeen students were Hispanic; one was black. The mean IQs of the groups were not significantly different (Experimental $M=92.2$; Control $M=93.75 ; p>.05$ ).

\section{Procedures}

Before assignment to condition, participants were tested individually by assessors (blind to condition) on the Dynamic Indicators of Basic Early Literacy Skills (DIBELS; see description below), a writing task (assessed after the conclusion of the study with the Six Traits Writing Rubric), and the lexical decision task. Interventions were given to participants in both conditions during the school district's five-week (25 days, six hours a day) summer school program.

\section{Measures}

After completion of the five-week intervention, the pre-measures listed above (the DIBELS, writing samples, and the lexical decision task) were readministered. Interviews were conducted with five of the participants and their families before the intervention and with four of the five same families to see if there had been any changes in their attitudes towards school and their performance in school. Follow-up data on reading skills (using the DIBELS) was collected four months later from all participants on reading skills using the DIBELS. See Figure 1 for a simplified timeline of the study events.

The Dynamic Indicators of Basic Early Literacy Skills (DIBELS; Kaminski, Cummings, Powell-Smith, \& Good, 2008) is a standardized measure used by many school districts in the United States to assess children on reading accuracy, fluency, and comprehension. It is designed to be short (one minute) and to monitor progress in accuracy and fluency at a particular grade level. A teacher times a student for one minute while they read a passage and marks the amount of errors they make while reading. Words that are omitted or substituted, and hesitations longer than three seconds are marked as errors. Words that are self-corrected within three seconds are scored as correct. A certified teacher blind to condition used the school district's protocol and materials for administering DIBELS benchmark testing on three separate passages at all three timepoints (pre-test, post-test, and follow-up); the three resulting oral fluency scores at each timepoint were averaged to calculate a mean Oral Reading Fluency score.

The Six Traits Writing Rubric (Six Traits Writing Rubric, 2014) is a scoring tool widely used to assess student writing using a set of criteria and standards (see Appendix A for the 
writing prompt used and Supplemental Appendix A to see the rubric used). It assesses students on the following six traits: ideas and content, organization, voice, word choice, sentence fluency, and conventions. Participants in this study were only assessed on voice and word choice; these traits were considered to be sensitive to intervention effects because of its focus on developing awareness of thought, emotion, and body awareness. An exemplary score in the voice category (6 out of 6 points) meant that a student's writing was expressive, engaging, sincere, had a strong sense of audience, and showed emotion, humor, honesty, suspense or life. An exemplary score in the word choice category meant that a student's words were precise, carefully chosen, and contained strong, fresh, vivid images. A certified teacher blind to condition scored participants' pre- and post-writing samples on voice and word choice using the Six Traits Writing Rubric.

The lexical decision task (cf. Julca, Nenert, Chaix, \& Demonet, 2010) is a computerized task that involves words, pseudo-words (pronounceable, meaningless letter sequences; e.g., "gad" and "foge"), pseudo-homophones (words that sound the same as a real word but are spelled differently; e.g., "yoo" and "aftir”), and pseudo-homophones (unpronounceable sequences of letters). Two lists of 120 items were created in order to have different stimuli in each session; these lists were balanced for lexical frequency, number of letters, and syllable structure. List order was randomly selected during each of the three blocks/session (40 words each block). Subjects were asked to indicate if the letter sequence presented was a real word by pressing one of two designated keys on the keyboard. Two types of data were collected from this measure: accuracy and response times (RT). RT outliers were defined as fast responses $(<200$ $\mathrm{ms}$ ) or slow responses ( $>2.5$ standard deviations above the group mean).

Heart rhythm coherence biofeedback. Research using heart rhythm coherence biofeedback with students in the classroom has found improvements in academic performance, behavior, and emotional wellbeing (McCraty, 2005). The Institute of HeartMath has developed biofeedback technology that teaches individuals how to self-induce a state of psychophysical coherence - a highly efficient mode associated with increased synchronization between the sympathetic and parasympathetic nervous systems, improved emotional stability, and enhanced cognitive performance. Interactive hardware/software monitored and displayed heart rate variability (HRV) patterns as students practiced breathing mindfully. Heart rhythm patterns became smoother and more wave-like as the practitioner's state of coherence increased (see 
Figure 2). Note: we were not able to screen extraneous variables that may have affected coherence ratios, e.g., medication, stress at home, etc.

Running records are an individually-administered assessment of reading accuracy, error rate, patterns of effective and ineffective strategy use, and self-correction rate (see Supplemental Appendix B for an example). It is a method developed by Marie Clay (2017) used to document reading progress over time and can be used to document self-talk during the child's reading of any text. The teacher uses the data to determine if the child is ready to advance to a new reading level. See Table 2 for a summary of dependent measures used in this study.

\section{Intervention}

During the intervention, all participants completed 10-15 minutes daily of computerized training using research-based software (SoundReadingSolutions: http://soundreading.com/) that included exercises in phonics, phonemic awareness, orthography (i.e., spelling), and fluency. The control group also completed 10-15 minutes daily of phonetic and orthographic activities with a trained research assistant. The experimental group received 30-45 minutes of literacy instruction and mindfulness. Students were taught how to use strategies (e.g., context cues and phonetic cues) to decode text, with mindfulness employed as a metacognitive strategy to ameliorate symptoms of cognitive interference, fatigue, and anxiety that arose during instruction. Writing samples, running records, and heart rhythm patterns were collected daily.

The components of the experimental intervention were grounded on the first author's 17 years of experience as a special education teacher who worked primarily with students who had learning disabilities. She has practiced mindfulness for 15 years and has 9 years of experience using the lens of cognitive psychology to conduct research on the effects of mindfulness with children. Because of her experience with both mindfulness and LD, the first author designed and conducted the intervention herself so she could investigate the integration of mindfulness practice into literacy instruction when students became upset or distressed or confused. When participants became upset or anxious during the process of reading and writing, the first author encouraged them to use mindfulness strategies to increase their awareness of negative thoughts, emotions, physical sensations, and behaviors that interfered with their learning (for more information on the intervention, see Understanding the Intervention under Qualitative Results below).

\section{Data Analysis}


Quantitative data analyses consisted of independent sample $t$-tests and follow-up tests on the dependent variables (decoding accuracy, fluency, voice, word choice, heartrate and coherence), to see whether the independent variables of group (mindfulness vs. control) and time of test (before, after, and 4 months following the intervention) influenced the dependent variables. Difference scores (subtracting the first score from the last score) are reasonably reliable for determining whether or not an intervention works (Trafimow, 2015).

Qualitative data was collected from nine face-to-face interviews (see Supplemental Appendix $\mathrm{C}$ for interview questions used), participant journals and drawings, Individual Education Plans (IEPs), and 500 pages of researcher field notes/reflections written during the intervention. The data was then loaded into a software package (Dedoose Version 6.1.9, 2015) for sorting and analysis. Within Dedoose, an open coding process was used to develop general conceptual categories. The first author read all the documents, highlighting excerpts and creating codes based on first impressions of the relevance and importance of the excerpt to the research questions (Merriam, 2009), coding these excerpts with multiple themes regarding participant characteristics, instructional strategies, and behavioral/academic improvements.

\section{Results}

We investigated the link between mindfulness practices and the amelioration of the symptoms of LD in children. We specifically wanted to know whether training in mindfulness, relative to control training, would result in decreasing anxiety and improvements in writing, reading, positive affect, self-awareness, self-efficacy, and use of metacognitive strategies. Overall, the results suggested that it did.

\section{Quantitative Results}

Analysis plan. Missing data (one lexical decision posttest) were estimated using Maximum Likelihood (Baraldi \& Enders, 2010). For the analysis of response times (RTs) for the lexical decision task, 60/4200 trials (1\%) were eliminated because the participant did not respond. RT outliers were defined as fast responses $(<200 \mathrm{~ms})$ or slow responses $(>2.5$ standard deviations above the group mean). One experimental participant's data were excluded from further analysis because 88/120 (73\%) of his RTs on the pretest and 49/120 (41\%) of his RTs on the posttest were either too slow or he did not respond. Altogether, 98/4080 (2.4\%) of the RTs from the remaining 17 participants were eliminated from the analysis: 18 were too fast and 80 were too slow. 
To determine overall improvement across the experiment as a function of condition (mindfulness vs. control), difference scores were calculated. Specifically, we subtracted the first test score from the last test score on three quantitative assessments of reading and writing. Independent sample $t$-tests on the group factor (experimental vs. control) were then conducted on these difference scores. Improvement in writing, reading, use of metacognitive strategies, and affect are discussed below.

Writing improvement. We wanted to know whether participant writing scores would improve, specifically in the areas of voice and word choice, as measured by the Six Traits Writing Rubric (n.d.). An improvement in voice meant that the student's writing became more expressive and showed more emotion, humor, honesty, or life. An improvement in word choice meant that the student used more strong, fresh, and vivid images in their writing. Although nonsignificant, experimental difference scores (reflecting overall improvement) were higher on the Voice test $\left(\operatorname{Exp} . M=1.60 ;\right.$ Control $\left.M=.00, t_{\text {diff }}(16)=-1.11 ; p>.05\right)$ and the Word Choice test $\left(\operatorname{Exp} . M=.50 ;\right.$ Control $\left.M=.25 ; t_{\text {diff }}(16)=-.49 ; p>.05\right)$. Cohen's $d$ was .52 for the Voice test (medium sized effect) and .23 (small effect) for the Word Choice test.

Reading improvement. We wanted to know whether participants would improve their accuracy and fluency while decoding text. There was no evidence of this from the DIBELS $t$-test difference scores (see Table 3). Although a non-significant result, the control group read an average of 4.59 more words than the experimental group on the DIBELS Oral Fluency Test. We hypothesize that the experimental participants were trying to use metacognitive strategies during decoding.

Improvement in use of metacognitive strategies. We wanted to know whether the intervention would increase mindfulness participants' use of metacognitive strategies while decoding text. During the intervention, students were encouraged to slow down, "use what they knew" about letters and sounds and pay attention to negative self-talk that might interfere with their performance. In other words, students were taught to become more reflective while decoding words, instead of just randomly guessing at words as fast as they could. Two results from the Word and Nonword lexical decision task indicated that difference scores on the response times were significantly longer in the experimental group than in the control group.

Nonwords on the lexical decision task included letter strings (e.g., "bkw"), pseudowords (e.g.,"weven"), and pseudohomophones (e.g., "heer"). Mean difference RTs on the Nonword 
subtest of the lexical decision task were longer in the experimental group (Exp. Nonword RT $M$ $=213, S D=548$; Control $M=-362, S D=599$; see Figure 3). The $t$-test on the lexical decision Nonword RTs approached significance, $t_{\text {diff }}(16)=2.07 ; p<.056, d=1.00$ (considered a large effect size, cf. Cohen, 1992).

Mean difference RTs on the Word subtest of the lexical decision task were longer in the experimental group (Exp. Word RT $M=310, S D=481$; Control $M=-300, S D=443$; see Figure 4). The $t$-test on the lexical decision Word RTs was highly significant; $t_{\text {diff }}(16)=2.71, p<.016$; $d=1.32$, (considered a very large effect size), indicating that participants who practiced mindfulness became more reflective when decoding words. We will elaborate more on the implications of this finding in the discussion section.

Affective Improvement. We wanted to know whether the mindfulness intervention would decrease anxiety in experimental subjects. This prediction was supported by the significant lowering of heartrate in the mindfulness group as measured by the HeartMath program.

The software analyzed and recorded heart rhythm patterns and calculated a coherence ratio for each session as either low, medium, or high. Low coherence is described as lower frequency, more chaotic heart rhythm patterns and increased average heart rate (McCraty, Atkinson, Tomasino, \& Bradley, 2006). Here is an explanation of how coherence is calculated by the HeartMath program (McCraty et al., 2006):

Heart rhythm coherence is reflected in the HRV power spectrum as a large increase in power in the low frequency (LF) band (typically around $0.1 \mathrm{~Hz}$ ) and a decrease in the power in the very low frequency (VLF) and high frequency (HF) bands. A coherent heart rhythm can therefore be defined as a relatively harmonic (sine-wave-like) signal with a very narrow, high-amplitude peak in the LF region of the HRV power spectrum and no major peaks in the VLF or HF regions. Coherence thus approximates the LF/(VLF + HF) ratio...First, the maximum peak is identified in the $0.04-0.26 \mathrm{~Hz}$ range (the frequency range within which coherence and entrainment can occur). The peak is then determined by calculating the integral in a window $0.030 \mathrm{~Hz}$ wide, centered on the highest peak in that region. The total power of the entire spectrum is then calculated. The coherence ratio is formulated as: (Peak Power/[Total Power-Peak Power] $)^{2}$. This method provides an 
accurate measure of coherence that allows for the nonlinear nature of the HRV waveform over time. (p. 8)

Linear contrasts were calculated on low and high coherence scores and average daily heartrate collected over 16 sessions (timepoints) from experimental participants by weighting each session (e.g., session 1 was weighted by multiplying by -15 , session 2 by -13 , session 3 by $11, \ldots$ session 16 by 15$)$. After calculating contrasts, confidence intervals were calculated and one-sample $t$-tests were conducted.

Linear contrast tests indicated no significant changes on low or high coherence levels over the course of the intervention: low coherence $M=-244 ; t(9)=-0.42, p>.05 ; 95 \%$ CI [$1551,1062]$; high coherence $M=-256 ; t(9)=-0.44, \mathrm{p}>.05 ; 95 \%$ CI $[-1562,1050]$.

The test on heartrate was highly significant; $M=-535 ; t(9)=-3.48, p=.007 ; 95 \%$ CI [$187,-883$ ] indicating that the average heartrate of experimental participants became significantly lower over time (see Figure 5).

\section{Qualitative Results}

Through the open coding process, three conceptually distinct and interconnected themes emerged pertaining to the researcher's understanding of the experimental group. Understanding the Participants (note: theme names are italicized from here on) leads to Understanding the Intervention, because the intervention was individualized to address needs and develop strengths. Understanding the Intervention leads to Understanding Improvements. (Note: The participants' names were changed to maintain confidentiality. The original spelling of the participants has been preserved — with bracketed corrections — when excerpts from their writing are used).

\section{Understanding the participants.}

Understanding the Participants includes three subthemes of Student Needs, Student Strengths, and Student Feelings.

Student needs. One overall need was Needs positive reinforcement (70 excerpts; see Supplemental Figure 1), or, as described in the researcher's codebook, the participant's need for affectionate, humorous, and playful rapport. Using a kind and playful tone with students improved their ability to respond positively to requests and increased awareness of their own behavior in a non-threatening manner. The greatest overall need was Behavioral, social (378 excerpts; see Supplemental Figure 2). Two of the most common behavioral themes in student records and observations were Hyperactive (42 excerpts) and Withdrawn or shut down (41 
excerpts) and included subthemes like Emotional intelligence (19 excerpts), or the need to identify and manage emotions. Students who were hyperactive or withdrawn were also Off-task (36 excerpts), a term that describes a student who is unwilling/unable to complete assignments.

Contributing to and sometimes exacerbating severe behavioral problems were significant language needs. Expressive language needs (116 excerpts; see Supplemental Figure 3), or the ability to successfully convey thoughts and feelings, was a frequent theme in student records, observations, and interviews, and was specifically addressed by encouraging students to explore thoughts/feelings during mindfulness breathing and then express them in writing.

Cognitive, reading, and writing needs. It is not surprising, in a sample of children with LD, that Cognitive needs (202 excerpts; see Supplemental Figure 4), Reading needs (200 excerpts; see Supplemental Figure 5) and Writing needs (251 excerpts; see Supplemental Figure 6) were common themes. Memory problems (70 excerpts) and Needs attention skills (64 excerpts) were the most frequently observed cognitive needs. Needs attention skills is directly related to Hyperactivity; three participants had been diagnosed with ADHD and two were taking medication during the intervention (ADHD meds: 18 excerpts). However, other students not labeled as ADHD also exhibited significant difficulties with the self-regulation of attention. Unable to focus on the task at hand, they shut down in the regular classroom and found other things to do (e.g., sharpening pencils repetitively or diving under desks to retrieve fallen objects). Memory problems also influenced Off-task behavior and Expressive language needs. Unable to remember directions or to find an answer to a question in their long-term memory, students became Aggressive (16 excerpts) and/or Defiant (26 excerpts) because they could not express their feelings/thoughts.

Cognitive problems directly impact reading problems. The most frequent reading need was Decoding (97 excerpts; see Supplemental Figure 7). Word blindness was observed when students miscued on words, reversing letters or seeing letters that were not there (e.g., one student read "holes" as if it had a "ch" at the beginning). Word slamming (11 excerpts), describes a behavior observed in four students. When decoding, they made rapid guesses or "slams" at the word, looking at the researcher's face for nonverbal cues to see if their guess was correct instead of using phonetic/contextual strategies.

Students with significant decoding problems are also not good spellers (Spelling; 133 excerpts). Three participants hated writing because they thought their handwriting was "bad" or 
"dumb" and another girl perseverated on letter formation, taking as long as ten minutes to write a simple sentence (Handwriting, 19 excerpts). Struggling to grip a pencil and print letters neatly also affected writing Fluency (28 excerpts), and so did expressive language difficulties and memory problems. If a child had problems coming up with original ideas, it impacted his ability to write fluently. Students who lacked emotional intelligence did not have voice (or distinct personality) and detail in their writing (e.g., they wrote sentences like this: "I am mad sad").

The behavioral and academic needs profile of the participants looks grim, but the strength profile, presented in the next section, offers hope that these children, after appropriate intervention, can still make valuable contributions to our society.

Student strengths. Many people_-scholars as well as lay people_associate LD with creativity (Wolff \& Lundberg, 2002), especially within the fine arts. They are said to have talents for seeing patterns in noise and pulling novel ideas out of the mundane (Chakravarty, 2009). In controlled studies, people with LD have been found to be better at visuospatial tasks, unusual or creative thinking measures like the Alternative Uses task, and artistic tasks like Picture Production (Attree, Turner, \& Cowell, 2009; Everatt, Steffert, \& Smythe, 1999; von Károlyi, 2001). Strengths identified by the school district, by parents, and by the children themselves correspond with these findings. Some participants said they liked Math (where visuospatial skills are important) and were better at it than reading and writing (19 excerpts). Cognitive tests by the school district often indicated strengths in "Nonverbal Ability" (i.e., visual processing and fluid intelligence). Nine of the students had average or above average nonverbal ability. Strengths in visuospatial ability (Observes visual details, 9 excerpts; Visual memory, 6 excerpts; Visual processing, 4 excerpts; see Figure 8) and Nonverbal reasoning (4 excerpts) were observed in this sample by the school district and the researcher. "I like all the rainbow colors!" said Clara about the room decorations.

Student feelings. Students with LD often experience higher levels anxiety than typical students (Fisher et al., 1996). Anxiety was the most frequently observed and/or reported negative feeling (80 excerpts; see Supplemental Figure 8). Anxiety was observed in nine of the experimental participants, especially during reading and writing, but only four self-reported being "worried," "scared," or "nervous because I can't read it." The other participants displayed anxious behaviors such as fidgeting, speeding up during reading, mumbling or whispering, or breathing quickly during mindfulness practice. Frustration (69 excerpts) was also a frequent 
negative feeling and may be due to increased effort made during tasks that require phonological processing (Maurer et al., 2007). Parents and teachers often reported a child becoming frustrated when they could not do a task, sometimes crying, hitting their foreheads, or putting their heads down and refusing to do anything else. Anger (60 excerpts) is a common response to frustration. During the intervention, Zach was frustrated and angry because his regular teacher had not let him write about his favorite video game. The researcher asked him to write about his feeling. "I am not gub [good] at writing. and I suke [suck] at writing." He turned his anger inward because of Low self-esteem (43 excerpts).

In contrast to the variety of negative feelings children expressed or demonstrated during the intervention, interviews, or in school records, the Positive Feelings (see Supplemental Figure 9) they displayed or talked about were simple: Happy, excited (82 excerpts), Pride, selfconfidence (33 excerpts), and Calm (24 excerpts). Interestingly, only 7 out of the 139 positive feelings excerpts came from school records. Teachers and evaluators were more likely to report negative feelings and behaviors than positive ones.

Understanding the intervention. This includes three subthemes: HeartMath, Academic, and Mindfulness Strategies. After examining school records and collecting background information during the pre-interviews, the first author created individual intervention plans for each student and used the following instructional strategies.

HeartMath instructional strategies. During each student's first session, they were introduced to the HeartMath program - how to put the ear sensor on their ear (to get heartrate information from their pulse) and shown how their HRV pattern was "jagged" when they started talking or got distracted and became smoother as they focused on taking deep breaths (see Figure 2).

It is not easy to teach children how to concentrate on their breathing. The most frequent difficulty that participants had during HeartMath was caused by High arousal (68 excerpts; see Supplemental Figure 10). When students were excited or silly (13/68 excerpts), restless or distracted (46/68 excerpts), or had a high average heartrate (9/68 excerpts), they found it difficult to increase their coherence level and tended to fidget, disrupting their ear Sensor connection (10 excerpts). It was also difficult for them to concentrate during periods of Low arousal (18 excerpts) — when they were mind-wandering or daydreaming (3/18 excerpts in Low arousal) or tired (15/18 excerpts). 
Breathing problems (24 excerpts) included holding their in-breath (4/24 excerpts), shallow breathing through their chest instead of deep breathing with their stomach $(8 / 24$ excerpts), taking fast, short breaths instead of longer ones (3/24), and having a cough (2/24) or stuffy nose (7/24). The researcher tried a variety of strategies to address these problems, the most common of which were Breathing lessons (105 excerpts; see Supplemental Figure 11) and Visualization (31 excerpts) — having subjects visualize bubbles (14 excerpts), floating on water (11 excerpts), their mother's smiling face (5 excerpts), and being kind to another child (5 excerpts). The youngest children, who were not able to concentrate for more than a minute at a time, were asked to set daily Breathing goals (25 excerpts). "How many breaths can you do today? Ten? Or twenty?" One boy with ADHD found it easier to focus with his Feet on a ball (3 excerpts). Progressive relaxation, or tensing and relaxing the muscles (Relax, 3 excerpts), was used with two students who had trouble reaching high levels of coherence; this practice seemed helpful. One boy said it felt "like [getting] a shot but my arms not numb."

Daily collection of HRV informed the researcher about the psychophysical effects of breathing lessons and helped to inform instruction on breathing (see Supplemental Figure 12). Many of the students, who were initially intrigued watching their HRV and coherence levels on the HeartMath display, became stressed about their performance. The researcher asked these students to lie on a Mat (27 excerpts) and Close eyes (3 excerpts) so they could not see the screen. Fawn wrote that when she was lying on the mat, she was calm, not thinking about anything and not "more worried because I was goin to get more red" [a red gauge on the display indicated low coherence; a green gauge indicated high]. Using breathing Visuals (20 excerpts)— blowing bubbles ( 6 excerpts), blowing on a pinwheel (3 excerpts), moving a cotton ball to a "goal" by blowing through a straw (5 excerpts), and breathing with a stuffed animal on their stomach (6 excerpts) - helped children see the effects of making their breath softer or more forceful. Asking students to Smell a fragrant flower (3 excerpts) encouraged them to breathe in more deeply. Pushing their breath out (3 excerpts), breathing In nose, out mouth (7 excerpts), and placing their Hands on stomach (7 excerpts) helped them become more aware of in-breaths and out-breaths. The two youngest students were asked to Count breaths (15 excerpts) out loud as they breathed in and out through a straw that the researcher held her hand over to feel their out-breaths. 
Every session began with HeartMath. After focusing on breathing for a few minutes, children started reading and writing.

\section{Academic instructional strategies.}

The academic strategy used most frequently was Using child's interests to motivate (75 excerpts; see Supplemental Figure 13). Before the intervention, children filled out an interest inventory. Then we ordered books in the areas of their interest to motivate them to read and write. For example, for a boy who liked making things, we ordered a paper airplane kit, with a book of instructions and diagrams. For a girl who loved clothes and shopping, we ordered "A Smart Girl's Guide to Style" (Cindrich, 2010) and "Paper Fashions" (Editors of Klutz, 2006).

One intervention strategy commonly used with children with LD is Multisensory instruction (34 excerpts) - using more than just the visual/auditory channels when presenting and practicing new concepts (i.e., using sense of smell, taste, or touch) to strengthen memory traces (e.g., spelling words in colored sand or shaving cream). Setting learning goals (29 excerpts) included teaching Clara, who took as long as 10 minutes to write six words, how to ignore distraction by making it into a game. "Can you ignore me stomping around the room and slamming doors while you write a sentence? How long do you think it will take you to write your sentence today?"

Decoding and writing strategies. Visual Focus (31 excerpts), Context Clues (27 excerpts), and Phonics (26 excerpts) were the three decoding strategies used (see Supplemental Figure 14). Because of difficulties noted earlier in Decoding needs (Word blindness and Word slamming), five Visual focus strategies were used. The first one was Tracking strips or finger (14 excerpts) — children were directed to use their finger to "point to the words" or put a paper strip under the words to block distractions and guide their eyes to the print. For students that repeatedly miscued on a word (e.g., reading "bears" as "babies"), the word they were saying (e.g., "babies") was written on a sticky note and placed next to the word in the text so they could see they were saying something different (Sticky note corrections, 7 excerpts). "It's okay if you read the word as 'babies' instead of 'bears," they were told, "but you have to point to the sticky note instead of the word on the page." For some reason, they did not like doing this; it motivated them to correct themselves so they could pull off the sticky note. Sometimes the researcher would Cover the word (4 excerpts) and say, "You're saying the word 'could' instead of 'can.' What letter would be at the end of 'could'? Does this word have a 'd' at the end of it?" Finding 
words (3 excerpts) meant asking students how often they could find a high-frequency word in a book and Word shapes (3 excerpts) meant outlining a word so students noticed the word's shape.

Does that make sense? (13 excerpts) was the most common of the Context Clues used. When they could not sound out a word, students were prompted to look at the words around it and think about what they knew. In one of the post-interviews, a boy remembered this strategy as thinking "it doesn't sound right." Some of the Phonics strategies included the traditional Sounding out (8 excerpts) strategy where students said the sound of each letter in a word, breaking up long words into syllables (Syllabication, 7 excerpts) and looking at Word families (3 excerpts) or groups of words that have a common pattern that makes them rhyme. All of these decoding strategies involved training children to slow down, look carefully at the word, and think about what they knew.

All of the students had difficulty with writing, especially spelling. One Writing Strategy (see Supplemental Figure 15) used with some of the most challenged spellers was Word bank (9 excerpts) - favorite words were kept in a "bank" of index cards and these words were drawn from the bank when needed. Since writing letters was difficult for two students, Kinesthetic letter formation (18 excerpts) was focused on with them. They formed letters with their bodies or wrote "the biggest letter you can" on the white board or rolled letter shapes out of clay. Writing on white board (15 excerpts) with dry erase markers was also helpful because they struggled with the mechanics of writing with cheap school materials - pencils that broke easily and erasers that smudged and often ripped holes in the paper. In addition to these academic strategies, the first author often incorporated mindfulness strategies while they were reading/writing to help them become aware of anxiety that arose during academic tasks.

Mindfulness strategies. Most of the mindfulness strategies used can be categorized as Awareness (278 excerpts; see Supplemental Figure 16), of which there were eight types. Instruction in Emotional awareness (134 excerpts; see Supplemental Figure 17) is important for children with LD because they often experience higher levels of anxiety than non-LD peers, especially during difficult academic tasks. Many of the participants also lacked Emotional intelligence; before the intervention started, they knew that some parts of school were "hard" for them but were not aware of anxiety while reading/writing. Participants worked on emotional awareness daily by choosing a Feelings Flashcard (Parr, 2010) illustrating a cartoon character feeling "calm" or "lonely" or "sad." Then they wrote about that feeling in their journals. Another 
way Emotional and Body awareness (74 excerpts) was increased was by pointing out — in a friendly, nonjudgmental, "this is interesting" way - that they were yawning, fidgeting, tightening their jaw, or displaying other emotions while working on a task. Sometimes they were asked what they were thinking during breathing practice or give reasons for their feelings to increase Thought awareness (23 excerpts).

Strength (21 excerpts) and Disability (10 excerpts) awareness were worked on by telling students when they were doing something well and giving them nonverbal, visuospatial opportunities to express themselves creatively (e.g., drawing or making things with clay). When Juan became tired while reading, the first author told him his brain was working very hard to read and that was why he took frequent "brain breaks" by talking about his video games.

Other mindfulness strategies used were Acceptance, Transfer, Modeling, Energy, and Writing dialogues. Nonjudgmental Acceptance (27 excerpts) is a critical component of mindfulness practice. Instead of becoming angry or irritated with students for negative behaviors, the researcher expressed compassion and understanding. For example, when Ángel was so depressed that he could not even choose an emotion flashcard, she said to him, "Is it hard to think sometimes?" He nodded his head to indicate "yes." When students were trying to decode a word, remember something, or talking about a distressing home situation, she instructed them to use breathing to help them with academic and home situations (Transfer, 39 excerpts). She used Modeling (17 excerpts) to show children when to breathe (by taking a loud in-breath when they became nervous) or how to talk about feelings or thoughts. She used strategies to increase their Energy (10 excerpts) when they were tired by teaching them how to breathe quickly and energetically. Finally, Writing dialogues (8 excerpts, see Supplemental Appendix D for an example) were used with three of the students during the last days of the intervention. Students who had trouble verbalizing their emotions but could write fluently enjoyed answering questions about the color, shape, size, temperature, intensity, and thoughts of their emotions by writing a few words or drawing a picture in response to questions.

Understanding the Intervention or the instructional strategies used may help in Understanding the Improvements observed and/or documented.

Understanding the improvements. In this section, we will discuss our study questions in light of our qualitative data. 
Improvement in reading and use of metacognitive strategies. We wanted to know if mindfulness instruction would improve literacy skills and use of metacognitive strategies while decoding text. We found improvements in Self-corrections (12 excerpts; see Supplemental Figure 18)—when a student realizes a decoding error and corrects it without prompting. Improvements in use of Metacognitive strategies (12 excerpts) were observed when students used context clues to figure out a word without prompting. Improvements in Reading level (8 excerpts) and Accuracy (5 excerpts) are supported by evidence from individual Running Records data for participants (see Supplemental Data: Running Records Figures 1-11). Improvement in Phonemic awareness (7 excerpts) could be seen when students who were very reluctant to "sound out" words began to do so on their own. Students demonstrated that they were Learning phonetic rules (6 excerpts) like the "silent e" rule. A boy who could only read ten words correctly at the beginning of the summer tripled the Number of words read (2 excerpts) accurately in a book by summer's end.

Writing improvement. The greatest improvement in writing was in Voice and detail (38 excerpts; see Supplemental Figure 19). Improvements in Self-expression (43 excerpts) transferred into use of more vivid detail in their writing. Fawn wrote about how she felt while she was reading. "The thing that is happens in my body is my head start to tingol [tingle]. I am thinking about if I get the wards [words] wron I fill [feel] nervous." Paz, who hated his handwriting and wrote very little independently showed improvement in writing Fluency (9 excerpts) during a post-interview when he showed us he had started drawing and writing at home. Improvement in Timeliness (6 excerpts) was evident in Clara, who at first took ten minutes to write a short sentence; she was able to reduce this time to less than eight minutes. Improvement in Spelling sounds (6 excerpts) was especially noticeable with Paz, whose writing was unreadable at the beginning. After five weeks, he could write this sentence without any help: "Im shy mi frst day uv hl klas" [I am shy my first day of my whole class].

Affective improvement. We wanted to know if positive affect during instruction would increase while negative emotions like anxiety and frustration would decrease. Mindfulness instruction resulted in Increases in Positive Affect (58 excerpts; see Supplemental Figure 20). Every day, students practiced mindfulness breathing from 1-4 minutes, and then often wrote about a positive emotion they felt during the HeartMath session, including Peace and calm (29 excerpts), Relaxation (15 excerpts), Happiness and fun (6 excerpts), and Compassion (4 
excerpts). Ana wrote that when she was breathing, she was singing a Katy Perry song in her mind "and I felt come [calm] lik [like] if I was sliping [sleeping]." Ernesto wrote that he was thinking about being a bubble when he was breathing. Sam wrote about being an otter sleeping in the water, taking deep breaths and floating. "It would be relaceind [relaxing]... you coud just heaier [hear] the water making wafes [waves]." Sam, who was very detached and indifferent at the beginning of the intervention discovered a strong feeling of compassion when visualizing a boy with no friends. Participants also found that mindfulness breathing Helps with negative emotions (4 excerpts), like Ernesto, who said he used breathing to help him when he was feeling sad at home.

Improvements in self-awareness and self-efficacy. Improvement in self-awareness can be seen in Thought, emotional awareness improvements (59 excerpts; see Supplemental Figure 21) and Body awareness improvements (21 excerpts). In a post-interview, while showing his father his coherence scores on HeartMath, Zach said: "On these two [days], I got really good because I was really excited. Right here I had a lot of blue because on the first day I was pretty nervous so I had some red here." Improvements in Self-efficacy (25 excerpts) were evident in participants as the intervention progressed. When asked why his coherence levels were high that day, one boy said, "because I'm proud of myself."

Another reader with severe disabilities did not like reading at the beginning of the intervention. When asked why, he said, "Cause I gotta read the words." He was eight years old and still did not know all of his letter sounds and was decoding at a kindergarten level. He became very anxious when asked to read, and often rushed through a book, reciting the text instead of reading it. Towards the end of the intervention, when asked how confident he was about reading on a scale from 1 to 3 , he chose 8 , he read four books, and sounded out the word "can" without prompting. He did not want to leave that day. "I'll make you read books all day," the researcher teased him. "I can read all day!" he exclaimed.

\section{Summary of Results}

Disregarding the quantitative results with very low effect sizes $(d<0.05)$, the data suggest that training in mindfulness had some behavioral benefits for children diagnosed with learning difficulties, including a decrease in anxiety, increase of reflective processing during decoding, and improvement in voice and word choice during writing tasks. 
Qualitative themes from this study are presented in Supplemental Figure 22 as the code application word cloud provided by the software package we used to analyze the qualitative data (Dedoose Version 6.1.9, 2015). In the word cloud, themes or codes that were most frequent appear in the largest size font (e.g., the most frequent code was Instruction in emotional awareness with 134 excerpts so it is in the largest font). Themes appear in random order, clustered around the largest themes.

The qualitative themes with the largest number of excerpts give a "big picture" of the intervention and its participants. Major components of the mindfulness intervention were Instruction in emotional awareness (134 excerpts) and Instruction in body awareness (74 excerpts). Many participants had Difficulty with oral or self-expression (116 excerpts), needed Concentration or attention skills (64 excerpts), had Difficulty remembering or retaining information (70 excerpts), and experienced Anxiety (80 excerpts) and Frustration (69 excerpts) during academic tasks like reading and writing. However, during the intervention, students were usually Happy and excited (82 excerpts), perhaps because a key instructional strategy employed was Using a child's interests (75 excerpts) to motivate them to learn. By the end of the intervention, participants showed Improvement in thought, emotion awareness (59 excerpts), and Improvement in reading (73 excerpts).

\section{Implications and Future Research Directions}

This section outlines implications of the major findings for educators and researchers working in the field of learning disabilities. We will discuss the implications to interventions and to assessment, specifically speed testing.

\section{Applications to Intervention: Metacognitive strategies}

We found that experimental participants' response times (RTs) in the lexical decision task increased significantly more than the control groups RTs, indicating a possible increase in reflectiveness and/or metacognition due to training in executive processes (self-regulation of attention) and awareness of self-attributional beliefs. Using mindfulness practices to become aware of self-talk during academic tasks could perhaps kill two birds with one stone - train children to regulate both attention and emotion. Children are constantly talking to themselves and others while completing (or not completing) classwork. For children with LD, this self-talk is mostly negative. Awareness of self-talk during academic tasks (e.g., when one participant wrote in his journal, "I suk at rding" [suck at writing]) in the presence of a nonjudgmental, 
accepting observer enables the child to examine the truth of their self-talk. For example, before the intervention, one participant said he hated writing and he did not like reading words. When the first author asked him, "Do they [his teachers] say you're very good at anything?" the boy answered, "Not really. No one say anything like that." After the intervention, this boy's self-talk had changed a little. When we asked him what he was good at, he said, "I don't have no idea now. I'm not good at writing or drawing or reading, yet." One practice implication for educators and researchers is to record at-risk children's self-talk during academic tasks in their regular or special education classrooms and determine whether an intervention could be implemented that might change negative attributional beliefs. Mindfulness as a metacognitive strategy for training executive processes and attributional beliefs by becoming aware of one's thought processes and emotions without attempting to change such thoughts and emotions could be a useful intervention for other researchers investigating metacognition, problem-solving, and academic progress in children with learning disabilities.

In this study, response times during a decoding task (i.e., the lexical decision test) became significantly longer in experimental participants after the intervention, indicating increased reflectiveness or use of self-regulatory processes. They were perhaps reflecting on prior knowledge about letter-sound relationships, focusing their attention on the letters, and/or monitoring their own emotional state or thoughts. Future research using fMRI might be helpful to investigate brain activation during decoding tasks after a mindfulness intervention that focused on developing thought, emotion, and body awareness. However, a focus on increasing reflectiveness in children may be counterproductive in a school system that consistently emphasizes quantity over quality — or speed over thoughtfulness.

\section{Application to Assessment: Speed Testing}

Our study findings suggested that training in metacognitive strategies increased children's reflectiveness during decoding. However, one of the study measures we used — the Dynamic Indicators of Early Literacy Skills (DIBELS) — penalizes children for reflection during decoding.

The DIBELS is a reading test used in many schools across the United States. It is comprised of six subtests, all designed to be administered in one minute (e.g., Letter Name Fluency and Oral Reading Fluency). Children from kindergarten to third grade take these tests at least three times a year. Teachers are required to use the results of the DIBELS to create reading groups and design lesson plans. The DIBELS was used in this study because it was the 
standardized reading test used by the state and the school where this study took place. The New Mexico Public Education Department (2016) declared on its website that the DIBELS was "brief, efficient, cost-effective, individually administered, standardized, and formative" (para. 2).

Dr. Goodman (2006), Professor Emeritus of Language, Reading, and Culture at the University of Arizona, has written a book entitled, The Truth about DIBELS: What it is, what it Does. According to Goodman, the authors of the DIBELS assume that a few minutes of reading or identifying letters or sounding out nonsense words can holistically represent progress in reading development. The authors of the DIBELS (Kaminski et al., 2008) affirm that, like other general outcome measures, the DIBELS is an efficient measure that takes only a few minutes to administer and score and yet still provides data that is highly relevant to instructional planning.

The authors of the DIBELS believe that formalized reading instruction (and formalized testing) should begin in kindergarten (Kaminski et al., 2008). Almost as soon as a five-year-old begins kindergarten, she is timed on how many alphabet letters she can read in a minute. Just as she is getting used to the task, the timer interrupts her. Many early childhood educators and researchers question whether it is developmentally appropriate to have formalized reading instruction and testing at this young age. As Goodman (2006) writes:

Should five-year-olds be repeatedly tested with timed tests? Should those who can't perform on these one-minute tests be drilled on naming letters and sounding out words while their classmates play? And should children come to see themselves as failures before they even start first grade? (p. 11)

The use of timed tests gives an advantage to the learner who is impatient, impulsive, energetic, or drilled for the DIBELS. Learners who are slow, reflective, thoughtful, careful, distractible, talkative, and/or inquisitive will be more likely to have lower scores. Also, children who are in the process of discovering that reading needs to make sense will also read more slowly as they try to make sense out of what they read.

In response to the criticism that the DIBELS measures are about speed and not real reading, the authors of the DIBELS (Kaminski and Cummings, 2007) wrote:

For all timed measures, the timing is as unobtrusive as possible. A silent count-down timer is used and no attention or emphasis is given to the timing aspect of the assessment. Most students are not even aware that timing is occurring. Students are never told to read 
as fast as possible; the DIBELS directions clearly state that students are to "do your best reading." ... It doesn't do anyone any good to do something wrong, very, very fast. (p. 4) However, in the first author's decade of experience administering the DIBELS, she has not seen "unobtrusive" timing — students know that timing is occurring. Teachers are told to share the results with students immediately. Students learn that it does not matter how they read, but instead, how many words they read. So, instead of trying to figure out an unknown word, they skip over it in the race to read only the words they know. And, since the test protocol is to give students the answer if they pause for more than three seconds, some children learn to wait for the word instead of trying to figure it out themselves.

Kaminski and Cummings (2007) argue that the DIBELS measures are timed because they are a test of fluency. The ability to read smoothly and confidently is a skill that is critical for the development of skilled reading (National Reading Panel, 2000) and systematic observation helps teachers assess reading proficiency and determine instructional goals (Hudson, Lane, \& Pullen, 2005). But is the DIBELS Oral Reading Fluency test the best assessment for emerging readers, who are far from fluent? In our study, four of the longest increases in response times came from emerging readers - readers who understand basic sound/symbol relationships and have learned some high-frequency words, but are reading at a very early level. They are not fluent readers at this stage. And yet it is common practice with these emergent readers, who, because they fail to meet benchmarks, to test them monthly or even weekly with this fluency test, a constant reminder to them of their reading failure.

Another implication for educators and researchers who are investigating or implementing mindfulness training and/or other metacognitive strategies to help ameliorate the symptoms of learning disabilities: they need to be aware that the transfer of such strategy training to the classroom may be impeded by the frequent use of timed tests like the DIBELS and the national stress on the importance of speed over thoughtfulness.

\section{Application to Assessment and Interventions: Testing Anxiety}

In our study, the chronic stress of continual standardized testing may have been relieved by mindfulness practice, as indicated by the significant decrease in the experimental students' heart rate over the course of the intervention. Future research could investigate whether or not heart rate remained low after breathing practice, especially during reading/writing. 
The perception of a perceived threat (e.g., when the child hears the Beep! Beep! Beep! of the DIBELS timer) causes the release of adrenaline, which increases heart rate and muscle tension and raises blood pressure. Repeated stimulation of the stress-response system over long periods of time can cause numerous mental and physical problems including anxiety, depression, sleep problems, impairment of memory and concentration, high blood pressure, irregular heart rhythms, digestive problems, and a weakened immune system (Cleveland Clinic, 2013; Mayo Clinic, 2013).

Breathing slowly can reverse some of the adverse effects of stress by increasing oxygen saturation in the cells, alpha waves, and heart rate variability and by lowering heart rate, thereby releasing energy and improving cognitive abilities (Thompson, 2009). Educators and researchers endeavoring to improve the educational futures of children with learning disabilities need to remember that the present environment of continual standardized testing is extremely stressful for the underachieving child. They need to implement and/or continue to research more holistic methods for assessing children's academic skills and for relieving the stress of continual failure.

\section{Study Limitations}

One limitation of this study was the small sample size. One reason for the small sample size was the large amount of data that we collected per participant to answer our research questions. Other limitations were that heartrate measures were not collected from the control group, so the influence of practice effects cannot be determined and, because the first author was a participant observer (both interventionist and a data analyst), some bias may have entered into the qualitative analysis. However, several significant findings from this pilot study support the prediction that mindfulness training ameliorates symptoms of learning disabilities. Given promising results and the importance of the problem, we argue that future research is needed to investigate whether the results generalize to larger samples.

\section{Conclusion}

This work was intended to provide clinicians, teachers, and school districts with a research-based intervention that will enable students with learning disabilities to be more positive and productive. It was also intended to investigate more deeply how a metacognitive strategy (in this case, mindfulness) improved the mental and emotional capacities of children with LD (specifically in the areas of reading, writing, emotional wellbeing, and self-efficacy). Quantitative results suggested that participants became more reflective during decoding and their 
average heart rate declined over the course of the intervention. The latter finding may indicate reduced anxiety regarding reading, which could lead to further improvement later on. Qualitative results indicated that mindfulness can be a tool used by intervention researchers and educators to improve literacy, attention skills, use of metacognitive strategies, positive affect, self-expression, self-awareness, and self-efficacy. Future research and educational reform movements need to examine the high cost of timed tests on mental and physical health and on academic performance and find more holistic ways to assess the strengths and limitations of underachieving children. 


\section{References}

Alesi, M., Rappo, G., \& Pepi (2014). Depression, anxiety at school and self-esteem in children with learning disabilities. Journal of Psychological Abnormalities in Children, 3(3), 1-8. doi: 10.4172/2329-9525.100125

Alvarez, J. A., \& Emory, E. (2006). Executive function and the frontal lobes: A meta-analytic review. Neuropsychology Review, 16 (1), 17-42. doi: 10.1007/s11065-006-9002-x

Attree, E. A., Turner, M. J., \& Cowell, N. (2009). A virtual reality test identifies the visuo-spatial strengths of adolescents with dyslexia. Cyberpsychology and Behavior, 12, 163-168. doi: 10.1089/cpb.2008.0204

Aylward, E. H., Richards, T. L., Berninger, V. W., Nagy, W. E., Field, K. M., Grimme, A. C., . . . \& Cramer, S. C. (2003). Instructional treatment associated with changes in brain activation in children with dyslexia. Neurology, 61(2), 212-219. doi: 10.1212/01/WNL .0000068363 .05974 .64

Baraldi, A. N. \& Enders, C. K. (2010). An introduction to modern missing data analyses. Journal of School Psychology, 48, 5-37. doi: 10.1016/j.jsp.2009.10.001

Beauchemin, J., Hutchins, T. L., \& Patterson, F. (2008). Mindfulness meditation may lessen anxiety, promote social skills and improve academic performance among adolescents with learning disabilities. Complementary Health Practice Review, 13, 34-45. doi: $10.1177 / 1533210107311624$

Bishop, S. R., Lau, M., Shapiro, S., Carlson, L., Anderson, N. D., Carmody, J., . . Devins, G. D. (2004). Mindfulness: A proposed operational definition. Clinical Psychology: Science and Practice, 2(3), 230-241. doi: 10.1093/clipsy/bph077

Borkowski, J. G., Estrada, M. T., Milstead, M., \& Hale, C. A. (1989). General problem-solving skills: Relations between metacognition and strategic processing. Learning Disability Quarterly, 12(1), 57-70. doi: 10.2307/1510252

Bornstein, P. H. \& Quevillon, R. P. (1976). The effects of a self-instructional package on overactive preschool boys. Journal of Applied Behavior Analysis, 9, 179-188.

Chakravarty, A. (2009). Artistic talent in dyslexia: A hypothesis. Medical Hypotheses, 73, 569571. doi: 10.1016/j.mehy.2009.05.034 
Chambers, R., Lo, B. C. Y., \& Allen, N. B. (2008). The impact of intensive mindfulness training on attentional control, cognitive style and affect. Cognitive Therapy \& Research, 32, 303-322. doi: 10.1007/s10608-007-9119-0

Chiesa, A., Calati, R., \& Serretti, A. (2011). Does mindfulness training improve cognitive abilities? A systematic review of neuropsychological findings. Clinical Psychology Review, 31, 449-464. doi: 10.1016/j.cpr.2010.11.003

Cindrich, S. (2010). A smart girl's guide to style. Middleton, WI: American Girl Publishing.

Clay, M. (2017). Running records for classroom teachers $\left(2^{\text {nd }}\right.$ ed.). Portsmouth, NH: Heinemann.

Cleveland Clinic. (2013). Stress and heart disease. Retrieved from http://my.clevelandclinic.org

Cohen, J. (1992). A power primer. Psychological Bulletin, 112(1), 155-159. doi: 10.1037/00332909.

Connolly, C. (1969). The psychosocial adjustment of children with dyslexia. Exceptional Children, 36(2), 126-127.

Davidson, R. J., Kabat-Zinn, J., Schumacher, J., Rosenkranz, M., Muller, D., Santorelli, S. F., . . . Sheridan, J. F. (2003). Alterations in brain and immune function produced by mindfulness meditation. Psychosomatic Medicine, 65, 564-570. doi: 10.1097 /01.PSY.0000077505.67574.E3

Davidson, R. J. (2010). Empirical explorations of mindfulness: Conceptual and methodological conundrums. Emotion, 10(1), 8-11. doi: 10.1037/a0018480

Dean, R. S., \& Rattan, A. J. (1987). Measuring the effects of failure with learning disabled children. International Journal of Neuroscience, 37(1-2), 27-30. doi: 10.3109 /00207458708991798

Dedoose Version 6.1.9, web application for managing, analyzing, and presenting qualitative and mixed method research data (2015). Los Angeles, CA: SocioCultural Research Consultants, LLC (www.dedoose.com).

Eden, G. F., Jones, K. M., Cappell, K., Gareau, L., Wood, F. B., Zeffiro, T. A., . . \& Flowers, D. L. (2004). Neural changes following remediation in adult developmental dyslexia. Neuron, 44, 411-422. doi: 10.1016/j.neuron.2004.10.019

Editors of Klutz. (2006). Paper fashions. Palo Alto, CA: Klutz. 
Everatt, J., Steffert, B., \& Smythe, I. (1999). An eye for the unusual: Creative thinking in dyslexics. Dyslexia, 5, 28-46.

Fan, J., McCandliss, B. D., Sommer, T., Raz, A., \& Posner, M. I. (2002). Testing the efficiency and independence of attentional networks. Journal of Cognitive Neuroscience, 14, 340347. doi: 10.1162/089892902317361886

Fisher, B. L., Allen, R., \& Kose, G. (1996). The relationship between anxiety and problemsolving skills in children with and without learning disabilities. Journal of Learning Disabilities, 29(4), 439-446. doi: 10.1177/00222194602900412

Goodman, K. S. (2006). A critical review of DIBELS. In K.S. Goodman (Ed.), The truth about DIBELS: What it is, what it does (pp. 1-39). Portsmouth, NH: Heinemann.

Gresham, F. M., \& Elliott, S. N. (1990). Social skills rating system manual. Circle Pines, MN: American Guidance Service.

Harris, K. R., Graham, S., Brindle, M., \& Sandmel, K. (2009). Metacognition and children's writing. In D. J. Hacker, J. Donlosky, \& A. C. Graesser (Eds.), Handbook of Metacognition in Education (pp. 131-153). New York, NY: Routledge.

Hudson, R. F., Lane, H. B., \& Pullen, P. C. (2005). Reading fluency assessment and instruction: What, why, and how? The Reading Teacher 58(8), 702-714.

Jha, A. P., Krompinger, J., \& Baime, M. J. (2007). Mindfulness training modifies subsystems of attention. Cognitive, Affective, \& Behavioral Neuroscience, 7(2), 109-119. doi: 10.3758/CABN.7.2.109

Jha, A. P., Stanley, E. A., Kiyonaga, A., Wong, L., \& Gelfand, L. (2010). Examining the protective effects of mindfulness training on working memory capacity and affective experience in a military cohort. Emotion, 10, 54-64. doi: 10.1037/a0018438

Julca, M., Nenert, R., Chaix, Y., \& Demonet, J. (2010). Remediation effects on N170 and P300 in children with developmental dyslexia. Behavioural Neurology, 22, 121-129. doi: 10.3233/BEN-2009-0257

Kabat-Zinn, J. (2003). Mindfulness-based stress reduction (MBSR). Constructivism in the Human Sciences, 8(2), 73-107.

Kaminski, R., \& Cummings, K. D. (2007). DIBELS: Myths and facts. Dynamic Measurement Group, 1-16. 
Kaminski, R., Cummings, K. D., Powell-Smith, K. A., \& Good, R. H. III (2008). Best practices in using Dynamic Indicators of Basic Literacy Skills for formative assessment and evaluation. In A. Thomas \& J. Grimes (Eds.), Best Practices in School Psychology V. (pp. 1181-1204). Bethesda, MD: National Association of School Psychologists.

Lovett, M. W., Lacerenza, L., \& Borden, S. L. (2000). Putting struggling readers on the PHAST track: A program to integrate strategy-based remedial reading instruction and maximize outcomes. Journal of Learning Disabilities, 33(5), 458-476. doi: 10.1177 /002221940003300507

Majumdar, M., Grossman, P., Dietz-Waschkowski, B., Kersig, S., \& Walach, H. (2002). Does mindfulness meditation contribute to health? Outcome evaluation of a German sample. Journal of Alternative and Complementary Medicine, 8(6), 719-730. doi: $10.1089 / 10755530260511720$

Maurer, U., Brem, S., Bucher, K., Kranz, F., Benz, R., Steinhausen, H., \& Brandeis, D. (2007). Impaired tuning of a fast occiptio-temporal response for print in dyslexic children learning to read. Brain, 130, 3200-3210. doi: 1 0.1093/brain/awm193

Mayo Clinic. (2013). Chronic stress puts your health at risk. Retrieved from http://www.mayoclinic.com/health/stress/SR00001

McCraty, R. (2005). Enhancing emotional, social, and academic learning with heart rhythm coherence feedback. Biofeedback, 33(4), 130-134. Retrieved January 5, 2014, from http://humancair.com/image/pdf/Enhancing\%20Learning\%20 \%20with\%20heart\%20coherence\%2014-10-10.pdf

McCraty, R., Atkinson, M., Tomasino, D., \& Bradley, R. T. (2006). Heart-brain interactions, psychophysiological coherence, and the emergence of a system-wide order. Retrieved from http://www.HeartMath.com/wp-content/uploads/2014/04/coherent_heart.pdf

Meiklejohn, J., Phillips, C., Freedman, M. L., Griffin, M. L., Biegel, G., Roach, A., . . . Saltzman, A. (2012). Integrating mindfulness training into K-12 education: Fostering the resilience of teachers and students. Mindfulness, 3(4), 291-307. doi: 10.1007/s12671-01200945

Merriam, S. B. (2009). Qualitative research: A guide to design and implementation. San Francisco, CA: Jossey-Bass. 
New Mexico Public Education Department. (2016). What is DIBELS? Retrieved from http://ped.state.nm.us/ped/LiteracyEarlyChildhoodEd_K3plus_DIBELS.html

Parr, T. (2010). Feelings flashcards. San Francisco, CA: Chronicle Books.

Pritchard, S. C., Coltheart, M., Palethorpe, S., \& Castles, A. (2012). Nonword reading: comparing dual-route cascaded and connectionist dual-process models with human data. Journal of Experimental Psychology: Human Perception and Performance, 38(5), 12681288. Doi: $10.1037 / \mathrm{a} 0026703$

Raskind, M. H., Goldberg, R. J., Higgins, E. L., \& Herman, K. L. (1999). Patterns of change and predictors of success in individuals with learning disabilities: Results from a twenty-year longitudinal study. Learning Disabilities Research and Practice, 14, 35-49.

Sarason, I., Sarason, B., Keefe, D., Hayes, B., \& Shearin, E. (1986). Cognitive interference: Situational determinants and traitlike characteristics. Journal of Personality and Social Psychology, 51, 215-226.

Serra, M. J. \& Metcalfe, J. (2009). Effective implementation of metacognition. In D. J. Hacker, J. Donlosky, \& A. C. Graesser (Eds.), Handbook of Metacognition in Education (pp. 278298). New York, NY: Routledge.

Schunk, D. H. \& Pajares, F. (2001). The development of academic self-efficacy. In A. Wigfield, \& J. Eccels (Eds.), Development of achievement motivation (pp. 16-32). San Diego, CA: Academic Press.

Seyed, S., Salmani, M., Nezhad, F. M., \& Noruzi, R. (2017). Self-efficacy, achievement motivation, and academic progress of students with learning disabilities: A comparison with typical students. Middle East Journal of Rehabilitative Health, 4(2), e44558. doi: 10.5812/mejrh.44558

Six Traits Writing Rubric. (2014). Retrieved January 4, 2014, from http://6traitsofwriting.org /wp-content/uploads/2013/06/6-Traits-Writing-Rubric.jpg

Spielberger, C. D., Gorsuch, R. L., \& Lushene, R. E. (1970). Manual for the State-Trait Anxiety Inventory. Palo Alto, CA. Consulting Psychologist Press.

Steca, P., Abela, J. R. Z., Monzani, D., Greco, A., Hazel, N.A., Hankin, B. L. (2014). Cognitive vulnerability to depressive symptoms in children: The protective role of selfefficacy beliefs in a multi-wave longitudinal study, Journal of Abnormal Child Psychology, 42(1), 137-148. doi:10.1007/s10802-013-9765-5 
Swanson, S. \& Howell, C. (1996). Test anxiety in adolescents with learning disabilities and behavior disorders. Exceptional Children, 62(5), 389-397.

Tang, Y., \& Posner, M. I. (2009). Attention training and attention state training. Trends in Cognitive Sciences, 13(5), 222-227. doi: 10.1016/j.tics.2009.01.009

Tarrasch, R., Berman, Z., \& Friedmann, N. (2016). Mindful reading: Mindfulness meditation helps keep readers with dyslexia and ADHD on the lexical track. Frontiers in Psychology, 7, 578. doi: 10.3389/fpsyg.2016.00578

Thompson, C. (2009). You're breathing all wrong. Men's Journal. Retrieved from http://www.mensjournal.com/magazine/you-re-breathing-all-wrong-20130227

Trafimow, D. (2015). A defense against the alleged unreliability of difference scores. Cogent Mathematics 2, 1064626. doi: 10.1080/23311835.2015.1064626

Vago, D. R. \& Silbersweig, D. A. (2012). Self-awareness, self-regulation, and self-transcendence (S-ART): A framework for understanding the neurobiological mechanisms of mindfulness. Frontiers in Human Neuroscience, 6(292), 1-30. doi: 10.3389/ fnhum .2012 .00296

Vellutino, F. R., Fletcher, J. M., Snowling, M. J., \& Scanlon, D. M. (2004). Specific reading disability (dyslexia): What have we learned in the past four decades? Journal of Child Psychology and Psychiatry 45(1), 2-40. doi: 10.1046/j.0021-9630.2003. 00305.x

von Károlyi, C. (2001). Visual-spatial strength in dyslexia: Rapid discrimination of impossible figures. Journal of Learning Disabilities, 34, 380-391. doi: 10.1177 /002221940103400413

Wenk-Sormaz, H. (2005). Meditation can reduce habitual responding. Advances in mind-body medicine, 21(3/4), 33-49.

Wolff, U. \& Lundberg, I. (2002). The prevalence of dyslexia among art students. Dyslexia, 8, 3442. doi: 10.1002/dys.211

Zimmerman, B. J. \& Moylan, A. R. (2009). Self-regulation: Where metacognition and motivation intersect. In D. J. Hacker, J. Donlosky, \& A. C. Graesser (Eds.), Handbook of Metacognition in Education (pp. 299-316). New York, NY: Routledge. 


\section{Appendix A \\ Writing Prompt}

At pre-test, 10 of the students were asked to answer the following prompt with the word "happy" and 10 to answer with the words "mad/sad." At post-test, this was reversed so that students were writing about a different emotion for their second writing sample.

Think about a time you were happy or mad/sad. Think about what happened to make you feel happy or mad/sad. Write about it. Did someone do something to you? Or say something to you? What were you thinking that made you feel happy or mad/sad? What did happiness or madness/sadness feel like in your body? What did you do when you felt happy or mad/sad? 